\title{
A pilot study of Bifidobacterium breve in neonates undergoing surgery for congenital heart disease
}

Takako Umenai ${ }^{1,2+}$, Nobuaki Shime ${ }^{2,3^{*}+}$, Takashi Asahara ${ }^{4}$, Koji Nomoto $^{4}$ and Toshiyuki Itoi $^{5}$

\begin{abstract}
Background: Probiotics have currently been widely used in patients undergoing various types of surgeries and improved their clinical outcomes, while data in pediatric cardiac surgery have been lacking. We investigated the safety and effects on the intestinal microbiota of the probiotic Bifidobacterium breve in neonates undergoing surgery for congenital heart disease.
\end{abstract}

Methods: This pilot, randomized study was performed in a single-center, university hospital-based pediatric intensive care unit (PICU). Twenty-one neonates undergoing surgery for congenital heart disease at $>7$ days after birth were randomly allocated to two groups: group A received $3 \times 10^{9}$ colony-forming units (CFU)/day of enteral B. breve strain Yakult (BBG-01), which was started 1 week before and terminated 1 week after surgery $(n=10)$, and group B did not receive BBG-01 $(n=11)$.

Results: The characteristics of the patients were similar in both groups. The postoperative days until fulfillment of the criteria for discharge from the PICU tended to be fewer in group A (8 [7-8] days) than in group B (9 [8-14] days) $(p=0.10)$. Likewise, the postoperative days to enteral nutrition or achievement of caloric goal tended to be fewer in group A than in group B. The Bifidobacterium in fecal samples after initiating BBG-01 in group A were significantly higher in number than that in group B. Enterobacteriaceae were significantly fewer in group A than in group B immediately (7.0 [3.9-7.7] vs. 8.5 [8.0-9.1] $\log _{10}$ cells/g) and 1 week (7.7 [7.0-8.1] vs. 9.3 [8.6-9.5] $\log _{10}$ cells/g) after surgery ( $p<0.05$ for both comparisons). The number of Pseudomonas after 1 week was significantly lower in group A than in group B $(p=0.04)$. The concentrations of total organic and acetic acids were also significantly higher in group A than in group B. The postoperative course was uncomplicated and all neonates were discharged alive from the PICU.

Conclusions: The perioperative administration of a probiotic to neonates undergoing surgery for congenital heart disease was safe and significantly improved their intestinal environment. The positive effects of this treatment on clinically significant outcomes remain to be investigated.

Keywords: Probiotics, Neonates, Congenital heart surgery, Intestinal microbiota

\section{Background}

Surgery for congenital heart diseases is performed in neonates worldwide with high success rates [1]. Infections and acute organ failure remain important complications and causes of reoperation, prolonged hospitalization, and intensive care, which significantly increase the postoperative

\footnotetext{
* Correspondence: shime@koto.kpu-m.ac.jp

${ }^{\dagger}$ Equal contributors

${ }^{2}$ Department of Anesthesiology and Intensive Care, Postgraduate School of Medical Science, Kyoto Prefectural University of Medicine, Kyoto 602-8566, Japan

${ }^{3}$ Department of Emergency and Critical Care Medicine, National Hospital Organization Kyoto Medical Center, Kyoto 612-8555, Japan

Full list of author information is available at the end of the article
}

morbidity and mortality [2,3]. Neonates undergoing corrective or palliative cardiac surgery are at increased risk of mesenteric hypoxia due to oxygen desaturation and low cardiac output. These patients often receive antimicrobials for prophylactic or non-prophylactic indications. Moreover, the incidence of delayed enteral feeding due to respiratory or cardiovascular instability is high [4]. These factors, alone or in combination, may disrupt the intestinal microbiota and function of the intestinal barrier, followed by bacterial translocation and associated disorders $[5,6]$. 
Probiotics are live microorganisms that confer benefits to a host when administered in sufficient amounts [7]. They have been widely used in critically ill $[8,9]$ or cancerous patients undergoing surgery $[10,11]$ and allegedly improved their clinical outcomes. The beneficial effects are likely due to an enhanced immune response to pathogens, competition for nutrition with pathogenic bacteria, improved immunologic function of the intestinal barrier, and a downregulation of proinflammatory cytokines $[12,13]$.

Despite the putative therapeutic effects they confer to neonates at risk of intestinal failure, studies of probiotics in neonates undergoing neonatal surgery for congenital heart disease are scarce [14]. Therefore, in this pilot study, we examined the effects of the perioperative administration of probiotic bacteria, Bifidobacterium breve [15-17], on the intestinal microbiota and the clinical outcomes of neonates who underwent cardiac surgery.

\section{Methods}

\section{Patients}

This study was approved by the ethics committee for clinical investigation of Kyoto Prefectural University, School of Medicine (Kyoto, Japan). Between April 2007 and April 2010, neonates admitted to our pediatric intensive care unit (PICU) and scheduled to undergo cardiac surgery between 1 to 2 weeks after birth were enrolled in this study. After excluding patients who were expected to undergo surgery within 7 days $(n=3)$ or who had received mechanical ventilation $(n=4)$, we enrolled 24 patients for randomized analysis. Of those, data from 21 patients who actually underwent surgery after over 7 days of age were finally analyzed (Figure 1).
A signed informed consent was obtained from their parents. The patients were randomly assigned to group A, who received $3 \times 10^{9}$ colony-forming units (CFU)/ day of enteral $B$. breve strain Yakult (BBG-01), which was administered starting 1 week before and ending 1 week after surgery $(n=10)$, and group $B$, who did not receive BBG-01 $(n=11)$. BBG-01 was a live, freeze-dried probiotic, containing $10^{9}$ bacteria/g, and was generously provided by Yakult Central Institute for Microbiological Research under a written agreement. We chose the dose on the basis of previous pediatric studies, where BBG-01 was administered in doses ranging between $1 \times 10^{9}$ [15] and $4 \times 10^{9} \mathrm{CFU} /$ day [17].

All patients received prophylactic intravenous cefazolin, $25 \mathrm{mg} / \mathrm{kg}$ every $8 \mathrm{~h}$, for $24 \mathrm{~h}$, started immediately before the surgical incision. Enteral breast or artificial milk was fed upon the decision of the attending physicians, beginning with 1-2 ml/kg every $3 \mathrm{~h}$, and increased by $2 \mathrm{ml} / \mathrm{kg}$ with each feeding to a target of $8 \mathrm{ml} / \mathrm{kg}$ every $3 \mathrm{~h}$, if the gastric residuals were $<50 \%$ of the administered dose and in the absence of vomiting or diarrhea.

\section{Clinical endpoints}

We measured the rates of postoperative infections and the survival rate at the time of discharge from the PICU. We also counted the postoperative days until (a) the criteria for discharge from the PICU were fulfilled, (b) initiation of or candidacy for milk feeding, and (c) spontaneous defecation. The criteria for discharge from the PICU were the observation of stable vital signs and freedom from all indwelling lines, including the pericardial drains.

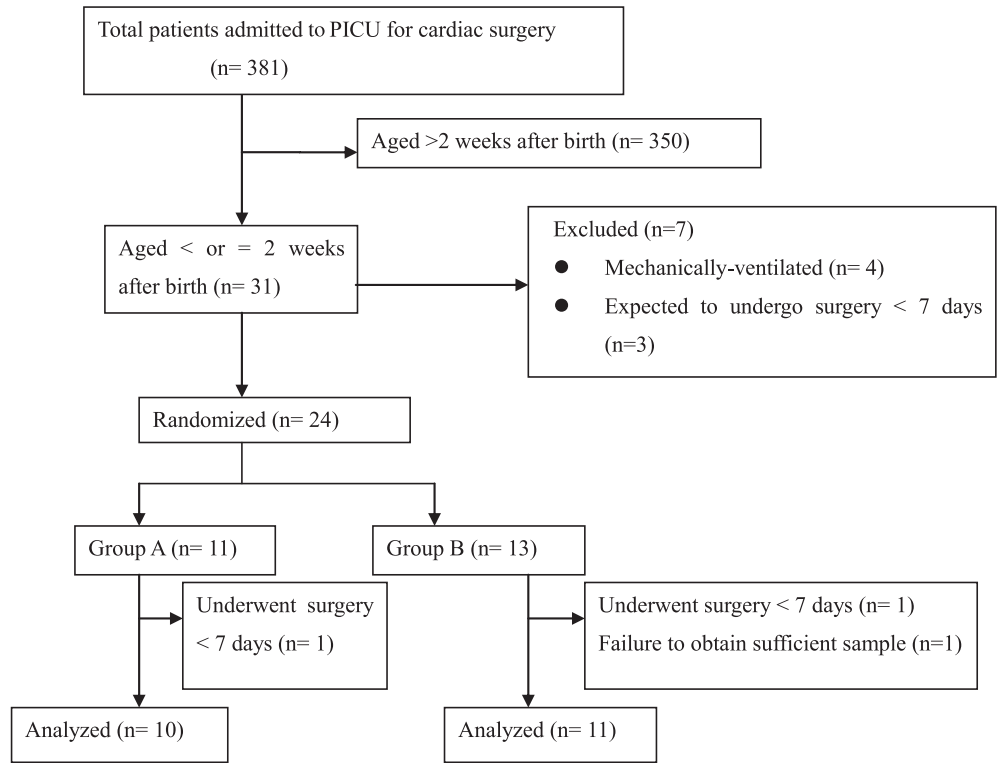

Figure 1 Flow diagram. A total of 21 patients were finally analyzed. PICU pediatric intensive care unit. 


\section{Fecal bacteriological examination Sample collection}

Fecal samples were collected (1) before the administration of BBG-01, (2) immediately before the operation, 1 week after the start of BBG-01 administration, (3) immediately after surgery, and (4) 1 week after the operation. For the sampling of the postoperative samples, we allowed delay $<48 \mathrm{~h}$ in cases of lacking defecation. Immediately after defecation, the samples were weighed and suspended in nine volumes of RNAlater ${ }^{\bullet}$ (Ambion Inc., Austin, TX, USA), an RNA stabilization solution, and then incubated for $10 \mathrm{~min}$ at room temperature.

\section{Isolation of total RNA or total DNA}

For RNA or DNA stabilization, $200 \mu \mathrm{l}$ of fecal homogenate was added to $1 \mathrm{ml}$ of sterilized phosphate buffer solution and then centrifuged at 5,000 $\mathrm{g}$ for $10 \mathrm{~min}$. The supernatant was discarded and the pellet was stored at $-80^{\circ} \mathrm{C}$ until used for the extraction of RNA or DNA. Methods described elsewhere were used to isolate RNA [18] and DNA [19]. Finally, the nucleic acid fraction was suspended in $1 \mathrm{ml}$ of nuclease-free water (Ambion Inc.).

\section{Bacterial count}

A standard curve was generated using reverse transcription-quantitative polymerase chain reaction (RT-qPCR) data, using the threshold cycle, the number of cycles when threshold fluorescence was reached, and the corresponding cell count, which was determined microscopically with 4,6-diamidino-2-phenylindole staining (Vector Laboratories, Burlingame, CA, USA) for the dilution series of the standard strains described elsewhere [18]. To determine the number of bacteria present in the samples, three serial dilutions of an extracted RNA sample were used for the RT-qPCR, and the threshold cycle values in the linear range of the assay were applied to the standard curve generated in the same experiment, to obtain the corresponding bacterial cell count in each nucleic acid sample, which was then converted to the number of bacteria per sample. The specificity of the RT-qPCR assay using group- or species-specific primers was determined as described previously [18]. The quantitative analysis of B. breve strain Yakult has been described elsewhere [19]. The detection limits were as follows: 5.0 cells/g for the Clostridium coccoides group, Clostridium leptum subgroup, Bacteroides fragilis group, Bifidobacterium, Atopobium cluster, and Prevotella, 2.1 cells/g for Clostridium perfringens, 2.1 cells/g for total Lactobacillus, 3.9 cells/g for Enterobacteriaceae, 3.9 cells/g for Enterococcus, 3.6 cells/g for Staphylococcus, 2.9 cells/g for Pseudomonas, and 6.0 cells/g for $B$. breve strain Yakult. We treated data below the detection limit as each detection limit for statistic analysis.

\section{Fecal organic acid concentrations and $\mathrm{pH}$}

A sample of the homogenized stool was isolated, weighed, mixed with $0.15 \mathrm{M}$ perchloric acid in a fourfold volume, and reacted for $12 \mathrm{~h}$ at $4{ }^{\circ} \mathrm{C}$. The mixture was centrifuged at $20,000 \mathrm{~g}$ for $10 \mathrm{~min}$ at $4^{\circ} \mathrm{C}$, and the supernatant was filtered with a $0.45-\mu \mathrm{m}$ membrane filter (Millipore Japan, Tokyo, Japan) and sterilized. The concentration of organic acids in the sample was measured using a Waters highperformance liquid chromatography system and 432 Conductivity Detector (Waters Co., Tokyo, Japan) and a Shodex Rspack KC-811 column (Showa Denko, Tokyo, Japan) $[11,16]$. We prepared a standard mixed solution containing 1 to $20 \mathrm{mM}$ of succinic, lactic, formic, acetic, propionic, isobutyric, butyric, isovaleric, and valeric acids and calculated the concentrations of these organic acids based on the standard curve. The stool $\mathrm{pH}$ was measured by inserting the glass electrode of a D-51 pH meter (Horiba Seisakusho, Tokyo, Japan) directly into the samples of homogenized stool. The detection limits were as follows: $0.075 \mu \mathrm{mol} / \mathrm{g}$ for succinic acid, $0.2 \mu \mathrm{mol} / \mathrm{g}$ for lactic acid, $0.05 \mu \mathrm{mol} / \mathrm{g}$ for formic acid, $0.4 \mu \mathrm{mol} / \mathrm{g}$ for acetic acid, $0.5 \mu \mathrm{mol} / \mathrm{g}$ for propionic acid, $0.55 \mu \mathrm{mol} / \mathrm{g}$ for butyric acid, $0.8 \mu \mathrm{mol} / \mathrm{g}$ for isovaleric acid, and $0.65 \mu \mathrm{mol} / \mathrm{g}$ for valeric acid. We treated data below the detection limit as each detection limit for statistic analysis.

\section{Statistics analysis}

The results are expressed as median [interquartile range (IQR)]. Mann-Whitney's $U$ test was used to compare between two groups, and comparison of the time-dependent data between two groups was performed using Wilcoxon's signed-rank test.

\section{Results}

The mean weights, gender distributions, and risk-adjusted congenital heart surgery (RACHS) category were similar, while the numbers of cardiac deformity involving aortic arch anomalies tended to be greater in group B (Table 1). No patient suffered complications from the probiotic administration.

\section{Clinical endpoints}

No patient died or developed necrotizing enterocolitis. One patient in group B developed an infection at the surgical site. The criteria for postoperative discharge from the PICU tended to be fulfilled earlier (8 [7-8] days) in group A than in group B (9 [8-14] days) ( $p=$ 0.10 ; Table 2). Likewise, the mean time to (a) initiation of or candidacy for enteral nutrition and (b) spontaneous defecation tended to be shorter in group A than in group B (Table 2). 
Table 1 Patient characteristics and congenital diseases

\begin{tabular}{|c|c|c|}
\hline & $\begin{array}{c}\text { Group A } \\
(n=10)\end{array}$ & $\begin{array}{c}\text { Group B } \\
(n=11)\end{array}$ \\
\hline Weight, kg & $2.9[2.8-3.0]$ & $3.0[2.9-3.1]$ \\
\hline Males & $5(50 \%)$ & $8(73 \%)$ \\
\hline \multicolumn{3}{|l|}{ Procedural times, min } \\
\hline Overall operation & $340[267-378]$ & $300[220-332]$ \\
\hline Cardiopulmonary bypass & 152 [138-200] & 167 [82-190] \\
\hline Anesthesia & 475 [395-503] & $400[298-428]$ \\
\hline RACHS category & $4[3-4]$ & $4[3-4]$ \\
\hline \multicolumn{3}{|l|}{ Congenital anomalies } \\
\hline Transposition of great vessels & 5 & 4 \\
\hline Interruption of the aortic arch & 1 & 3 \\
\hline Double outlet right ventricle & 2 & 0 \\
\hline Hypoplastic left heart syndrome & 0 & 2 \\
\hline Coarctation of the aorta & 2 & 1 \\
\hline $\begin{array}{l}\text { Total anomalous pulmonary venous } \\
\text { return }\end{array}$ & 0 & 1 \\
\hline \multicolumn{3}{|l|}{ Selected types of surgeries } \\
\hline Arterial switch & 6 & 4 \\
\hline Aortic arch repair & 3 & 4 \\
\hline Pulmonary arterial banding & 1 & 1 \\
\hline Norwood surgery & 0 & 1 \\
\hline $\begin{array}{l}\text { Total anomalous pulmonary venous } \\
\text { return repair }\end{array}$ & 0 & 1 \\
\hline
\end{tabular}

RACHS risk-adjusted congenital heart surgery. Values are median [IQR] or numbers (\%) of observations. No significant differences between the groups.

\section{Fecal microbiota}

No significant differences in total numbers of fecal microbiota were observed between the two groups (Table 3). The number of Bifidobacterium was significantly higher in group A than in group B throughout the courses. BBG-01, the probiotic administered, was isolated from the feces in group A only (Table 3). Concordantly, the number of Enterobacteriaceae in the $\log _{10}$ scale was significantly lower in group A than in group B, both immediately (7.0 [3.9-7.7] vs. 8.5 [8.0-9.1]) and 1 week (7.7 [7.0-8.1] vs. $9.3[8.6-9.5])$ after surgery $(p<0.05$ for both comparisons). The number of Staphylococcus 1 week after

Table 2 Clinical endpoints

\begin{tabular}{lccc}
\hline & $\begin{array}{c}\text { Group A } \\
(\boldsymbol{n}=\mathbf{1 0})\end{array}$ & $\begin{array}{c}\text { Group B } \\
(\boldsymbol{n}=\mathbf{1 1})\end{array}$ & $\begin{array}{c}\boldsymbol{p} \\
\text { value }\end{array}$ \\
\hline Duration of MV, h & $44[18-67]$ & $42[19-37]$ & 0.62 \\
Days until & & & \\
$\quad$ Discharge criteria fulfilled, days & $8[7-8]$ & $9[8-14]$ & 0.10 \\
$\quad$ Target enteral nutrition, days & $5[4-6]$ & $6[5-8]$ & 0.09 \\
$\quad$ Spontaneous defecation, days & $2[1-2]$ & $2[2-5]$ & 0.09 \\
\hline
\end{tabular}

$M V$ mechanical ventilation. Values are median [IQR]. surgery in the $\log _{10}$ scale was also significantly lower in group A than in group B (Table 3). The number of Pseudomonas after 1 week was significantly lower in group A than in group B $(p=0.04)$.

\section{Fecal organic acid concentration and $\mathrm{pH}$}

The total postoperative concentration of organic acids was significantly higher in group A than in group B and was significantly higher than the total concentration before initiating BBG-01 (Table 4). The significantly higher concentrations of acetic acid in group A than in group B both immediately and 1 week after surgery are particularly noteworthy (Table 4). Also, the concentration of acetic acid after initiating BBG-01 was significantly higher than that before initiating BBG-01. The fecal pH before initiating BBG-01 was significantly higher than that 1 week after surgery. Finally, the fecal $\mathrm{pH}$ tended to be lower in group A than in group B (before surgery $p=0.067$, immediately after surgery $p=0.067,1$ week after surgery $p=0.053)$.

\section{Discussion}

The perioperative administration of probiotics to neonates undergoing cardiac surgery was well tolerated and significantly improved their fecal microbiota, expressed by a higher detection rate of obligate anaerobe and concentration of organic acids and a lower $\mathrm{pH}$. The intestinal microbiota typically develops within 3 to $4 \mathrm{~h}$ after birth and stabilizes within approximately 2 weeks. Obligate anaerobes account for $>95 \%$ of the commensal microbiota, with Bifidobacterium as the predominant microorganism [6]. As observed in this study, the microbiota in neonates undergoing cardiac surgery may be disrupted below the detection limit throughout the perioperative period. By contrast, the administration of Bifidobacterium may successfully preserve the intestinal microbiota and decrease the presence of pathogenic Enterobacteriaceae significantly. This is concordant with previous studies, which found a decrease in Enterobacteriaceae after the administration of BBG-01 to Bangladeshi children $<5$ years of age [17]. The concentration of acetic acid, one of the short-chain fatty acids, was also significantly higher in recipients of BBG-01. Short-chain fatty acids are important anions in the colonic lumen, which influence both the morphology and function of the colonocytes, and their increase lowers the $\mathrm{pH}$, which indirectly modifies the composition of the colonic microbiota and increases the absorption of minerals [20]. Shin et al. have suggested that a low $\mathrm{pH}$ is important to decrease the incidence of infections due to the O157 subtype of Escherichia coli [21]. These changes in the intestinal environment might contribute to the trend of earlier postoperative recovery of enteral nutritional intake and defecation. A recent clinical study has also shown that perioperative administration of 
Table 3 Fecal microorganisms

\begin{tabular}{|c|c|c|c|c|c|c|c|c|}
\hline & & & & & Surg & ery & & \\
\hline & \multicolumn{2}{|c|}{ Before BBG } & \multicolumn{2}{|c|}{ Before } & \multicolumn{2}{|c|}{ Immediately after } & \multicolumn{2}{|c|}{1 week after } \\
\hline & Group A & Group B & Group A & Group B & Group A & Group B & Group A & Group B \\
\hline & $n=7$ & & $n=10$ & $n=11$ & $n=10$ & $n=11$ & $n=10$ & $n=11$ \\
\hline Total & 9.7 [8.9-9.9] (100) & NT & $9.8[9.1-10.2](100)$ & 9.7 [9.3-9.9] (100) & $9.9[9.5-10.6]^{* * * *}(100)$ & $9.8[8.7-10.0](100)$ & $9.9[9.5-10.1](100)$ & 9.8 [9.5-9.9] (100) \\
\hline \multicolumn{9}{|l|}{ Obligate anaerobes } \\
\hline Clostridium coccoides group & 8.7 [8.6-8.8] (29) & NT & $6.4[6.2-7.2](30)$ & $7.3[6.2-8.4](18)$ & $7.9[7.3-8.4](40)$ & $8.6[8.1-8.6](27)$ & $6.2[6.0-6.7](50)$ & $8.4[7.2-9.0](36)$ \\
\hline C. leptum subgroup & $6.3[6.2-6.3](29)$ & NT & $5.6[5.5-5.7](20)$ & $6.6[6.3-7.4](36)$ & $6.0[5.6-6.3](20)$ & $8.3[7.8-8.8](27)$ & $5.9[5.7-6.5](30)$ & $8.1[7.6-8.5](27)$ \\
\hline Bacteroides fragilis group & 9.5 [8.7-9.6] (71) & NT & $9.0[8.5-9.6](60)$ & $9.4[9.3-10.1](45)$ & $8.4[7.0-9.3](60)$ & $9.3[9.2-9.9](45)$ & $9.4[8.6-9.6](70)$ & $9.1[8.8-9.2](45)$ \\
\hline Bifidobacterium & $7.0[6.2-7.7](42)$ & NT & $9.5[9.0-9.8]^{* * * * *}(100)$ & $9.0[7.9-9.1](27)$ & $\begin{array}{l}9.7[9.4-10.2]^{* *} \\
* * *, * * * *(100)\end{array}$ & $8.9[8.8-9.6](45)$ & $9.7[9.2-9.9]^{* * * * *}(100)$ & 9.2 [8.9-9.6] (45) \\
\hline Bifidobacterium breve Yakult & $<6.0(0)$ & NT & $9.1[8.4-9.7]^{* * * * *}(100)$ & $<6.0(0)$ & $9.2[8.6-9.5]^{* * * * *}(100)$ & $<6.0(0)$ & $9.0[8.9-9.3]^{* *, * * *}(100)$ & $<6.0(0)$ \\
\hline Atopobium cluster & $7.9[7.4-7.9](42)$ & NT & $6.2[5.7-6.5](30)$ & $8.3[8.1-8.4](18)$ & $6.9[6.3-7.7](30)$ & $8.4[8.2-8.6](18)$ & $6.7[6.2-6.7](30)$ & 7.9 [7.5-8.2] (18) \\
\hline Prevotella & 6.2 [6.1-6.2] (29) & NT & $5.4[5.3-5.5](20)$ & $5.2(9)$ & $5.1(10)$ & $5.7(9)$ & $6.4(10)$ & $5.6(9)$ \\
\hline C. perfringens & $<2.1(0)$ & NT & $2.9(10)$ & $<2.1(0)$ & $<2.1(0)$ & $<2.1(0)$ & $2.7(10)$ & $2.7(9)$ \\
\hline \multicolumn{9}{|l|}{ Facultative anaerobes } \\
\hline Total Lactobacillus & 5.0 [5.0-5.9] (57) & NT & $5.4[5.1-5.7](20)$ & $3.2[2.9-3.3](27)$ & $4.3[3.6-4.9](60)$ & $3.2[2.7-3.3](27)$ & $4.7[3.9-4.8](60)$ & 3.7 [3.6-3.8] (27) \\
\hline Enterobacteriaceae & $8.6[8.2-8.7](71)$ & NT & $7.5[7.2-7.8](60)$ & 8.0 [7.8-8.8] (73) & $7.5[7.1-8.0]^{*}(60)$ & 8.5 [8.3-9.2] (82) & $7.7[7.0-8.1]^{* * * * * *}(90)$ & $9.4[8.9-9.6]^{* * * *}(91)$ \\
\hline Enterococcus & 8.7 [8.3-9.6] (71) & NT & 8.2 [6.7-9.0] (70) & 8.6 [8.2-9.5] (82) & $8.4[7.5-9.4]^{* * * *}(100)$ & 8.5 [8.2-8.8] (100) & $8.3[8.0-8.8](100)$ & 8.5 [7.9-9.5] (100) \\
\hline Staphylococcus & 8.1 [7.2-9.1] (71) & NT & $6.9[6.4-7.4](90)$ & 8.5 [6.3-9.0] (100) & $6.2[5.1-7.2]^{* * * *}(80)$ & 6.7 [5.5-7.2] (100) & $6.3[5.1-6.7]^{*}(100)$ & 7.2 [6.8-8.1] (100) \\
\hline \multicolumn{9}{|l|}{ Obligate aerobes } \\
\hline Pseudomonas & $4.3(14)$ & NT & $<2.9(0)$ & 3.5 [3.1-3.6] (27) & $3.4(10)$ & $3.5[3.5-3.5](18)$ & $<2.9(0)^{*}$ & $3.9[3.7-4.5](36)$ \\
\hline
\end{tabular}

Values are median $\log _{10}$ cells/g [IQR] (\% detection rate). NT not tested. ${ }^{*} p<0.05,{ }^{* *} p<0.01$ vs. group $B,{ }^{* * *} p<0.05$ vs. before initiating $B B G$, ${ }^{* * *} p<0.05$ vs. before surgery. 
Table 4 Fecal organic acid concentrations and pH

\begin{tabular}{|c|c|c|c|c|c|c|c|c|}
\hline & & & \multicolumn{6}{|c|}{ Surgery } \\
\hline & \multicolumn{2}{|l|}{ Before BBG } & \multicolumn{2}{|c|}{ Before } & \multicolumn{2}{|c|}{ Immediately after } & \multicolumn{2}{|c|}{1 week after } \\
\hline & Group A & Group B & Group A & Group B & Group A & Group B & Group A & Group B \\
\hline & $n=7$ & & $n=10$ & $n=11$ & $n=10$ & $n=11$ & $n=10$ & $n=11$ \\
\hline Total organic acids & $21.7[14.1-34.8](100)$ & NT & $52.6[29.7-64.9](100)$ & $31.9[26.2-62.9](100)$ & $61.3[51.5-99.8]^{* * * * * *}(100)$ & $40.7[17.1-48.5](100)$ & $95.2[61.0-105.4]^{* * * * *}(100)$ & $48.0[39.9-88.6](100)$ \\
\hline Succinic acid & $6.3[4.9-8.2](57)$ & NT & $10.6[8.6-14.2](70)$ & 16.2 [7.8-30.9] (73) & $3.5[1.3-15.0](70)$ & $11.2[7.2-21.7](45)$ & 9.4 [1.9-15.2] (90) & 3.3 [2.5-21.5] (64) \\
\hline Lactic acid & 10.0 [6.2-18.0] (57) & NT & 7.8 [3.0-15.5] (70) & $4.9[4.2-7.1](64)$ & $8.9[7.2-10.8](90)$ & $7.3[5.5-8.3](45)$ & $18.8[5.1-27.7](100)$ & $14.6[3.8-24.2](73)$ \\
\hline Formic acid & $3.6[2.4-4.7](29)$ & NT & $2.6[1.5-4.7](60)$ & $3.3[2.5-6.4](36)$ & 5.4 [3.9-5.9] (60) & $2.5[1.5-3.4](91)$ & $2.2[1.1-3.4](50)$ & $2.5[1.9-3.8](64)$ \\
\hline Acetic acid & $12.2[7.3-21.7](100)$ & NT & $\begin{array}{c}31.3[22.6-46.4] \\
* * *(100)\end{array}$ & $\begin{array}{c}20.1[16.6-29.4] \\
(100)\end{array}$ & $\begin{array}{c}46.9[41.0-69.0]^{* *} \\
* * * * * * *(100)\end{array}$ & $\begin{array}{c}20.4[10.3-31.0] \\
(100)\end{array}$ & $\begin{array}{c}53.8[39.7-73.4]^{*} \\
* * *(100)\end{array}$ & $\begin{array}{c}36.7[11.8-47.5] \\
(100)\end{array}$ \\
\hline Propionic acid & $0.9(14)$ & NT & $2.4[2.0-5.0](30)$ & $4.4[3.6-5.6](36)$ & $4.5[2.7-6.2](20)$ & 3.1 [1.9-4.2] (18) & $7.9[4.5-7.9](30)$ & $13.3[4.2-23.5](36)$ \\
\hline Butyric acid & $<0.55(0)$ & NT & $<0.55(0)$ & $0.8(9)$ & $<0.55(0)$ & $3.6[2.2-4.9](18)$ & $<0.55(0)$ & $2.9[1.7-4.2](18)$ \\
\hline Isovaleric acid & $<0.8(0)$ & NT & $<0.8(0)$ & $7.0(9)$ & $<0.8(0)$ & $<0.8(0)$ & $<0.8(0)$ & $2.7(9)$ \\
\hline Valeric acid & $<0.65(0)$ & NT & $<0.65(0)$ & $<0.65(0)$ & $<0.65(0)$ & $<0.65(0)$ & $<0.65(0)$ & $<0.55(0)$ \\
\hline $\mathrm{pH}$ & $6.7[6.4-7.4](100)$ & & $5.5[5.3-6.0](100)$ & $6.3[6.0-6.9](100)$ & $5.4[5.3-6.4](100)$ & $6.4[6.1-6.7](100)$ & $5.6[5.5-5.6]^{* * *}(100)$ & 6.0 [5.6-6.3] (100) \\
\hline
\end{tabular}

Values are median $\log _{10}$ cells/g [IQR] (\% detection rate). $N T$ not tested. ${ }^{*} p<0.05,{ }^{* *} p<0.01$ vs. group $B,{ }^{* * *} p<0.05$ vs. before initiating BBG, ${ }^{* * * *} p<0.05$ vs. before surgery. 
synbiotics in esophageal surgery facilitated enteral nutrition [22]. An earlier recovery of intestinal function is favorable, as it might prevent the malnutrition frequently observed in neonates presenting with congenital heart disease [5].

We used a B. breve strain Yakult as the probiotic, which is naturally resistant to cefazolin, an antimicrobial often used for surgical prophylaxis, and obtained significant recovery in fecal samples. Moreover, several clinical studies have shown its beneficial effects in children [15-17]. Kitajima et al. found that the early administration of $B$. breve significantly improved the function of the digestive tract and promoted weight gain in neonates [15]. Wada et al. observed a lower incidence of fever and fewer days of parenteral antimicrobial therapy in patients undergoing chemotherapy for pediatric malignancies [16]. Those indicate that the use of $B$. breve strain Yakult could be a possible option for perioperative use of neonatal heart surgery.

\section{Limitations}

The cardiac anomaly tended to differ among the groups. Group B contains more arch anomalies including interrupted aortic arch or hypoplastic left heart syndrome. Since arch anomalies might tend to cause intestinal ischemia and associated clinical morbidities, this difference might be contributed to clinical outcomes, rather than the administration of probiotics. The risk-adjusted congenital heart surgery (RACHS) categories, which represent surgical complexity and associated outcomes, however, were similar between the groups (Table 1).

\section{Conclusions}

While our observations suggest improvements in gut function conferred by the administration of $B$. breve, it was insufficient to draw any significant conclusions regarding its effect on the incidence of postoperative complications including infection or postoperative recovery. This might be inherent due to the nature of pilot study with small sample size. The clinical benefits of this intervention remain to be confirmed in larger, future trials.

\section{Competing interests}

The authors declare that they have no competing interests.

\section{Authors' contributions}

TU carried out the clinical data acquisition, performed the statistical analysis of clinical data, and drafted the manuscript. NS conceived the study, participated in its design and coordination, and helped draft the manuscript. TA and KN carried out the fecal examination and performed the statistical analysis of fecal examination. TI participated in the design of the study and revised it critically for important intellectual content. All authors read and approved the final manuscript.

\section{Acknowledgements}

We wish to express our sincere gratitude to Mr. Norikatsu Yuki and Mr. Akira Takahashi of the Yakult Central Institute for Microbiological Research for the valuable assistance in performing the bacterial flora analyses.

\section{Author details}

'Department of Anesthesiology, Shimada Hospital, Osaka 583-0875, Japan. ${ }^{2}$ Department of Anesthesiology and Intensive Care, Postgraduate School of Medical Science, Kyoto Prefectural University of Medicine, Kyoto 602-8566, Japan. ${ }^{3}$ Department of Emergency and Critical Care Medicine, National Hospital Organization Kyoto Medical Center, Kyoto 612-8555, Japan. ${ }^{4}$ Yakult Central Institute for Microbiological Research, Tokyo 186-8650, Japan.

${ }^{5}$ Department of Pediatric Cardiology and Nephrology, Postgraduate School of Medical Science, Kyoto Prefectural University of Medicine, Kyoto 602-8566, Japan.

Received: 21 February 2014 Accepted: 23 May 2014

Published: 5 June 2014

\section{References}

1. Bakshi KD, Vaidyanathan B, Sundaram KR, Roth SJ, Shivaprakasha K, Rao SG, Nair SG, Chengode S: Determinants of early outcome after neonatal cardiac surgery in a developing country. J Thorac Cardiovasc Surg 2007, 134:765-771.

2. Baker GM, O'Brien SM, Welke KF, Jacobs ML, Jacobs JP, Benjamin DK, Peterson ED, Jaggers J, Li JS: Major infection after pediatric cardiac surgery: a risk estimation model. Ann Thorac Surg 2010, 89:843-850.

3. Morgan CJ, Zappitelli M, Robertson CM, Alton GY, Sauve RS, Joffe AR, Ross DB, Rebeyka IM: Risk factors for and outcomes of acute kidney injury in neonates undergoing complex cardiac surgery. J Pediatr 2013, 162:120-127.

4. Wheat JC: Nutritional management of children with congenital heart disease. http://www.escholarship.org/uc/item/6jh767ps.

5. Pathan N, Burmester M, Adamovic T, Berk M, Ng KW, Betts H, Macrae D, Waddell S, Paul-Clark M, Nuamah R, Mein C, Levin M, Montana G, Mitchell JA: Intestinal injury and endotoxemia in children undergoing surgery for congenital heart disease. Am J Respir Crit Care Med 2011, 184:1261-1269.

6. Papoff P, Ceccarelli G, d'Ettorre G, Cerasaro C, Caresta E, Midulla F, Moretti C: Gut microbial translocation in critically ill children and effects of supplementation with pre- and pro biotics. Int J Microbiol 2012. doi.2012:151393.

7. Joint FAO/WHO Working Group: Guidelines for the evaluation of probiotics in food. London Ontario, Canada April 30 and May 1, 2002. $\mathrm{ftp}: / / \mathrm{ftp}$.fao.org/es/esn/food/wgreport2.pdf.

8. Barraud D, Blard C, Hein F, Marcon O, Cravoisy A, Nace L, Alla F, Bollaert PE, Gibot S: Probiotics in the critically ill patient: a double blind, randomized, placebo-controlled trial. Intensive Care Med 2010, 36:1540-1547.

9. Shimizu K, Ogura H, Goto M, Asahara T, Nomoto K, Morotomi M, Matsushima A, Tasaki O, Fujita K, Hosotsubo H, Kuwagata Y, Tanaka H, Shimazu T, Sugimoto H: Synbiotics decrease the incidence of septic complications in patients with severe SIRS: a preliminary report. Dig Dis Sci 2009, 54:1071-1078.

10. Ohigashi S, Hoshino $\mathrm{Y}$, Ohde S, Onodera H: Functional outcome, quality of life, and efficacy of probiotics in postoperative patients with colorectal cancer. Surg Today 2011, 41:1200-1206.

11. Usami M, Miyoshi M, Kanbara Y, Aoyama M, Sakaki H, Shuno K, Hirata K, Takahashi M, Ueno K, Tabata S, Asahara T, Nomoto K: Effects of perioperative synbiotic treatment on infectious complications, intestinal integrity, and fecal flora and organic acids in hepatic surgery with or without cirrhosis. JPEN J Parenter Enteral Nutr 2011, 35:317-328.

12. Asahara T, Nomoto K, Shimizu K, Watanuki M, Tanaka R: Increased resistance of mice to Salmonella enterica serovar Typhimurium infection by synbiotic administration of Bifidobacteria and transgalactosylated oligosaccharides. J App/ Microbiol 2001, 91:985-996.

13. Yasui H, Ohwaki M: Enhancement of immune response in Peyer's patch cells cultured with Bifidobacterium breve. J Dairy Sci 1991, 74:1187-1195.

14. Ellis $\mathrm{CL}$, Rutledge JC, Underwood MA: Intestinal microbiota and blue baby syndrome: probiotic therapy for term neonates with cyanotic congenital heart disease. Gut Microbes 2010, 1:359-366.

15. Kitajima H, Sumida Y, Tanaka R, Yuki N, Takayama H, Fujimura M: Early administration of Bifidobacterium breve to preterm infants: randomized controlled trial. Arch Dis Child Fetal Neonatal Ed 1997, 76:F101-F107.

16. Wada M, Nagata S, Saito M, Shimizu T, Yamashiro Y, Matsuki T, Asahara T, Nomoto K: Effects of the enteral administration of Bifidobacterium breve on patients undergoing chemotherapy for pediatric malignancies. Supp Care Cancer 2010, 18:751-759. 
17. Matsuda F, Chowdhury MI, Saha A, Asahara T, Nomoto K, Tarique AA, Ahmed T, Nishibuchi M, Cravioto A, Qadri F: Evaluation of a probiotics, Bifidobacterium breve BBG-01, for enhancement of immunogenicity of an oral inactivated cholera vaccine and safety: a randomized, double-blind, placebo-controlled trial in Bangladeshi children under 5 years of age. Vaccine 2011, 29:1855-1858.

18. Matsuda K, Tsuji H, Asahara T, Matsumoto K, Takada T, Nomoto K: Establishment of an analytical system for the human fecal microbiota, based on reverse transcription-quantitative PCR targeting of multicopy rRNA molecules. Appl Environ Microbiol 2009, 75:1961-1969.

19. Fujimoto J, Tanigawa K, Kudo Y, Makino H, Watanabe K: Identification and quantification of viable Bifidobacterium breve strain Yakult in human faeces by using strain-specific primers and propidium monoazide. J Appl Microbiol 2011, 110:209-217.

20. Hijova E, Chmelarova A: Short chain fatty acids and colonic health. Bratis/ Lek Listy 2007, 108:354-358.

21. Shin R, Suzuki M, Morishita Y: Influence of intestinal anaerobes and organic acids on the growth of enterohaemorrhagic Escherichia coli 0157:H7. J Med Microbiol 2002, 51:201-206.

22. Tanaka K, Yano M, Motoori M, Kishi K, Miyashiro I, Ohue M, Ohigashi H, Asahara T, Nomoto K, Ishikawa O: Impact of perioperative administration of synbiotics in patients with esophageal cancer undergoing esophagectomy: a prospective randomized controlled trial. Surgery 2012, 152:832-842.

doi:10.1186/2052-0492-2-36

Cite this article as: Umenai et al:: A pilot study of Bifidobacterium breve in neonates undergoing surgery for congenital heart disease. Journal of Intensive Care 2014 2:36.

\section{Submit your next manuscript to BioMed Central and take full advantage of:}

- Convenient online submission

- Thorough peer review

- No space constraints or color figure charges

- Immediate publication on acceptance

- Inclusion in PubMed, CAS, Scopus and Google Scholar

- Research which is freely available for redistribution 